\title{
Structural Evolution of Reversible Mg Insertion into a Bilayer Structure of V2O5-nH2O Xerogel Material
}

Niya Sa, ${ }^{\dagger *}$ Tiffany L. Kinnibrugh,, Hao Wang, ${ }^{\dagger \ddagger}$ Gopalakrishnan Sai Gautam, ${ }^{\S}$ Karena W. Chapman,, John T. Vaughey, ${ }^{\dagger \neq}$ Baris Key, ${ }^{\dagger \neq}$ Timothy T. Fister, ${ }^{\dagger}$ John W. Freeland,, Danielle L. Proffit, ${ }^{\dagger \neq}$ Peter J. Chupas, ${ }^{*}$ Gerbrand Ceder, ${ }^{\S}$ Javier G. Bareno, ${ }^{\ddagger}$ Ira D. Bloom, ${ }^{\ddagger}$ Anthony K. Burrell $^{\dagger *}$

†Joint Center for Energy Storage Research, Argonne National Laboratory, Lemont, IL 60439, USA

${ }^{\ddagger}$ Chemical Science and Engineering Division, Argonne National Laboratory, Lemont, IL 60439, USA

"X-ray Science Division, Advanced Photon Source, Argonne National Laboratory, Lemont, IL 60439, USA

${ }^{\S}$ Material Science Division, Lawrence Berkeley National Laboratory, Berkeley, California 94720, USA

KEYWORDS: Mg battery, bilayer $\mathrm{V}_{2} \mathrm{O}_{5}, \mathrm{Mg}$ intercalation, pair distribution function (PDF), solid state NMR

TGA analysis: Thermogravimetric analysis (TGA) of the pristine $\mathrm{V}_{2} \mathrm{O}_{5} \cdot \mathrm{nH}_{2} \mathrm{O}$ xerogel was conducted on a Perkin Elmer Pyris Instrument inside of an argon-filled glove box with $\mathrm{H}_{2} \mathrm{O}$ and $\mathrm{O}_{2}$ level less than $1 \mathrm{ppm}$. The weight change profile was characterized by a steep loss program before $80{ }^{\circ} \mathrm{C}$, followed with a gradual weight loss program with $3{ }^{\circ} \mathrm{C} / \mathrm{min}$ increase of temperature till $800^{\circ} \mathrm{C}$. Figure $\mathrm{S} 1$ showed weight loss profile that is composed of two parts, the first slope observed for weight loss before $150{ }^{\circ} \mathrm{C}$ which corresponds to weakly bound water and the second slope corresponds to tightly bound water.

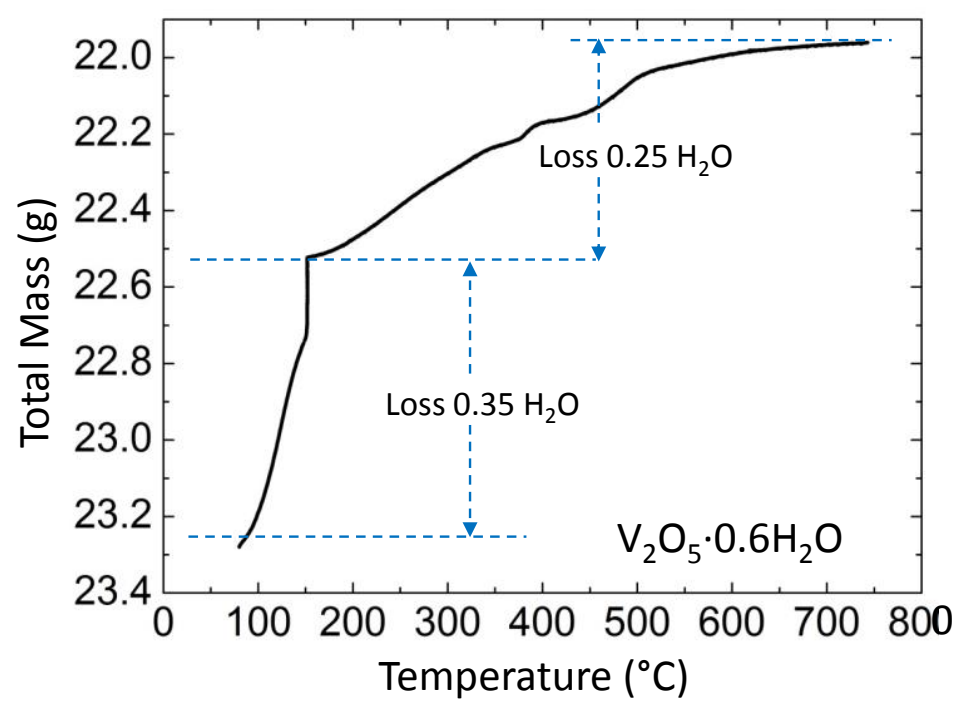

Figure S1. Thermogravimetric analysis (TGA) curves for pristine $\mathrm{V}_{2} \mathrm{O}_{5} \cdot \mathrm{nH}_{2} \mathrm{O}$ xerogel sample. Weight loss corresponding to weakly bond water $\left(\mathrm{T}<150^{\circ} \mathrm{C}\right)$ and tightly bond water $\left(\mathrm{T}>150^{\circ} \mathrm{C}\right)$ is shown. 

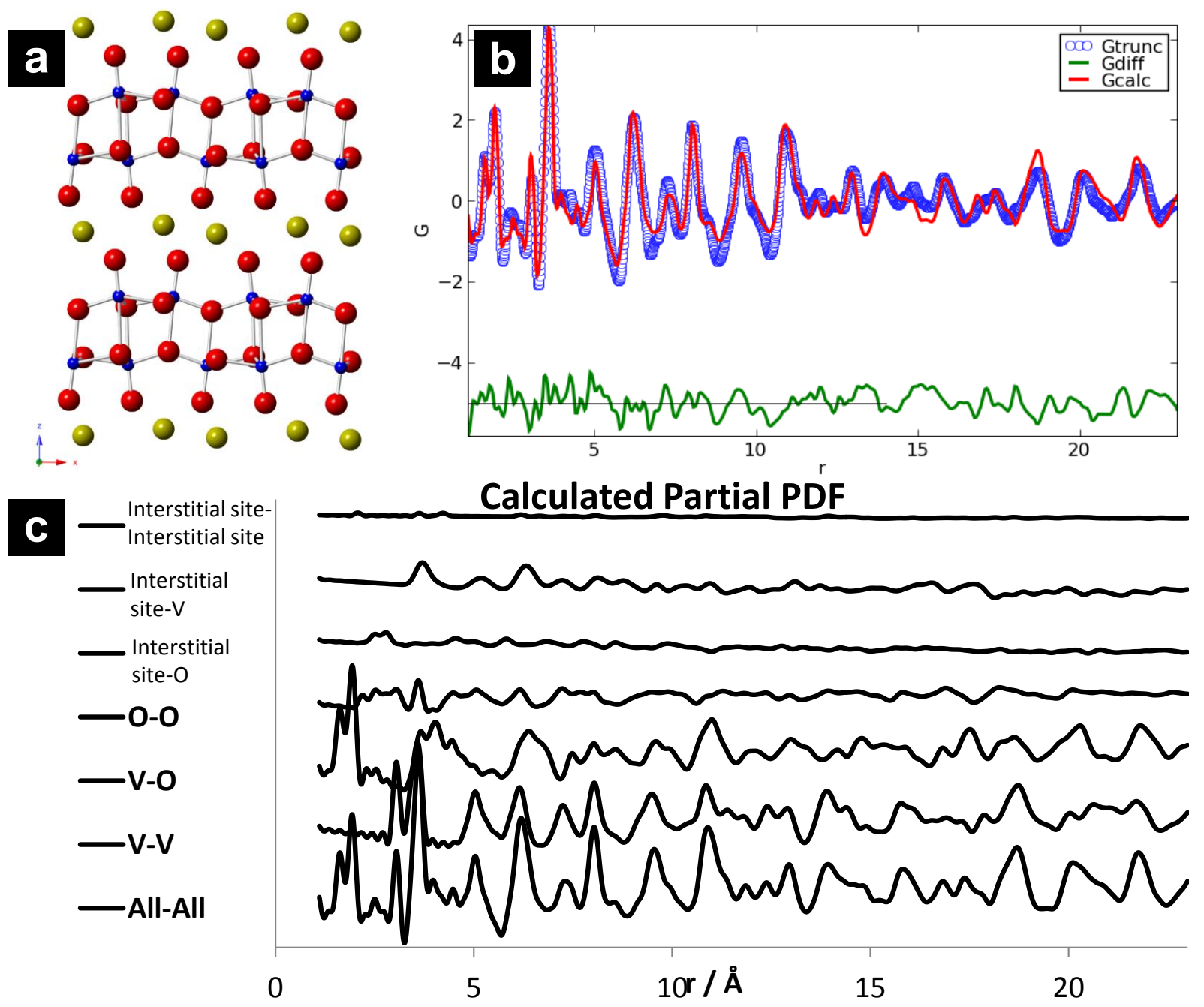

Figure S2. Pair distribution function (PDF) analysis for xerogel $\mathrm{V}_{2} \mathrm{O}_{5} \cdot \mathrm{nH}_{2} \mathrm{O}$. Structure model is based on $\mathrm{V}_{2} \mathrm{O}_{5} \cdot \mathrm{nH}_{2} \mathrm{O}$ with interstitial species. (a). Double layer structure of xerogel $\mathrm{V}_{2} \mathrm{O}_{5} \cdot \mathrm{nH}_{2} \mathrm{O}$, where red, yellow and blue stand for oxygen, water molecules and vanadium, respectively. (b). Experimental (hollow blue line) and calculated PDF (solid red line) for $\mathrm{V}_{2} \mathrm{O}_{5} \cdot \mathrm{nH}_{2} \mathrm{O}$ xerogel. (c). Calculated partial PDF for Interstitial site-interstitial site, Interstitial site- $\mathrm{V}$, Interstitial site-O, O-O, V-O, V-V over $20 \AA$. 


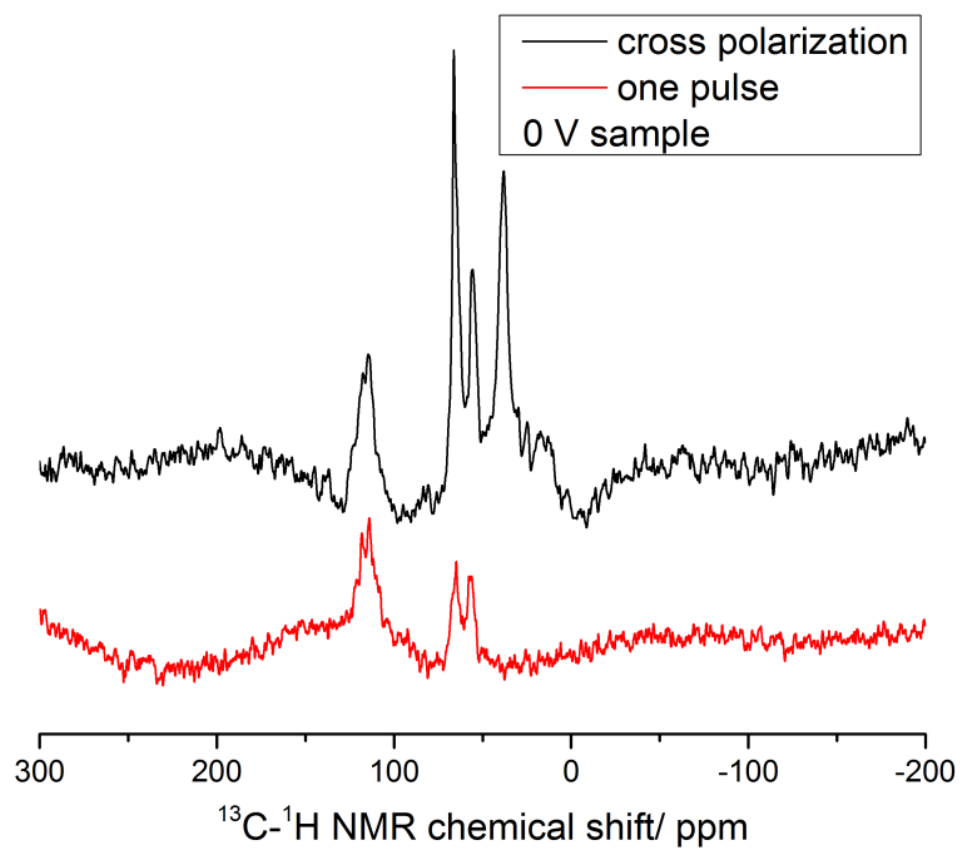

Figure S3. ${ }^{13} \mathrm{C}$ NMR spectra of discharged sample (0 V). black: one pulse experiment, red: ${ }^{1} \mathrm{H}-{ }^{13} \mathrm{C}$ cross polarization experiment.

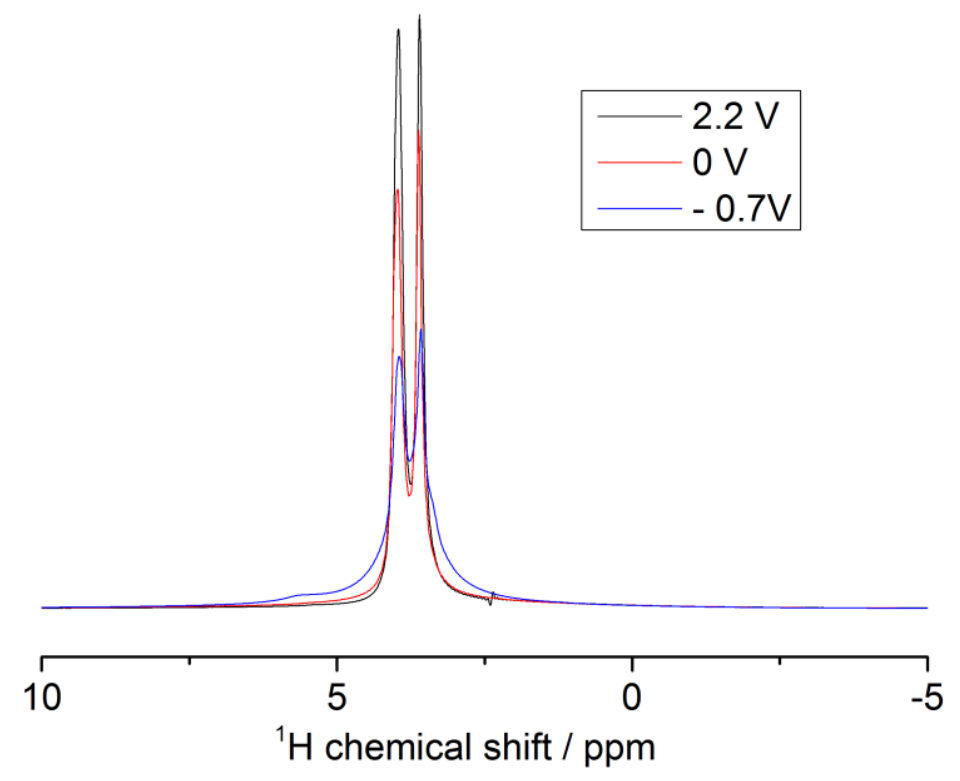


Figure S4: ${ }^{1}$ H NMR spectra of a secondary set of charged/discharged sample.

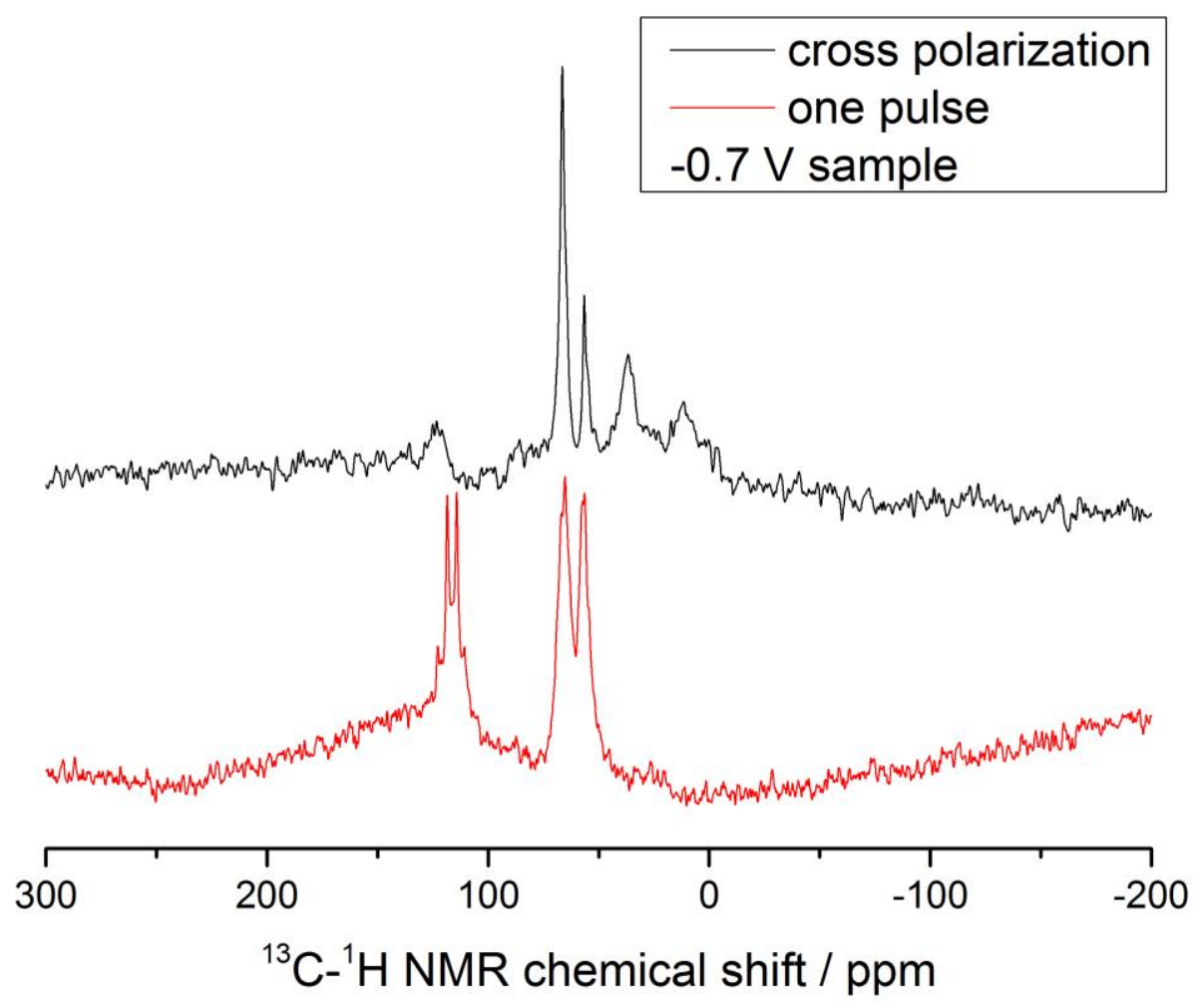

Figure S5. ${ }^{13} \mathrm{C}$ NMR spectra of the $-0.7 \mathrm{~V}$ sample in Figure S4. Black: ${ }^{1} \mathrm{H}-{ }^{13} \mathrm{C}$ cross polarization experiment, red: one pulse experiment. 


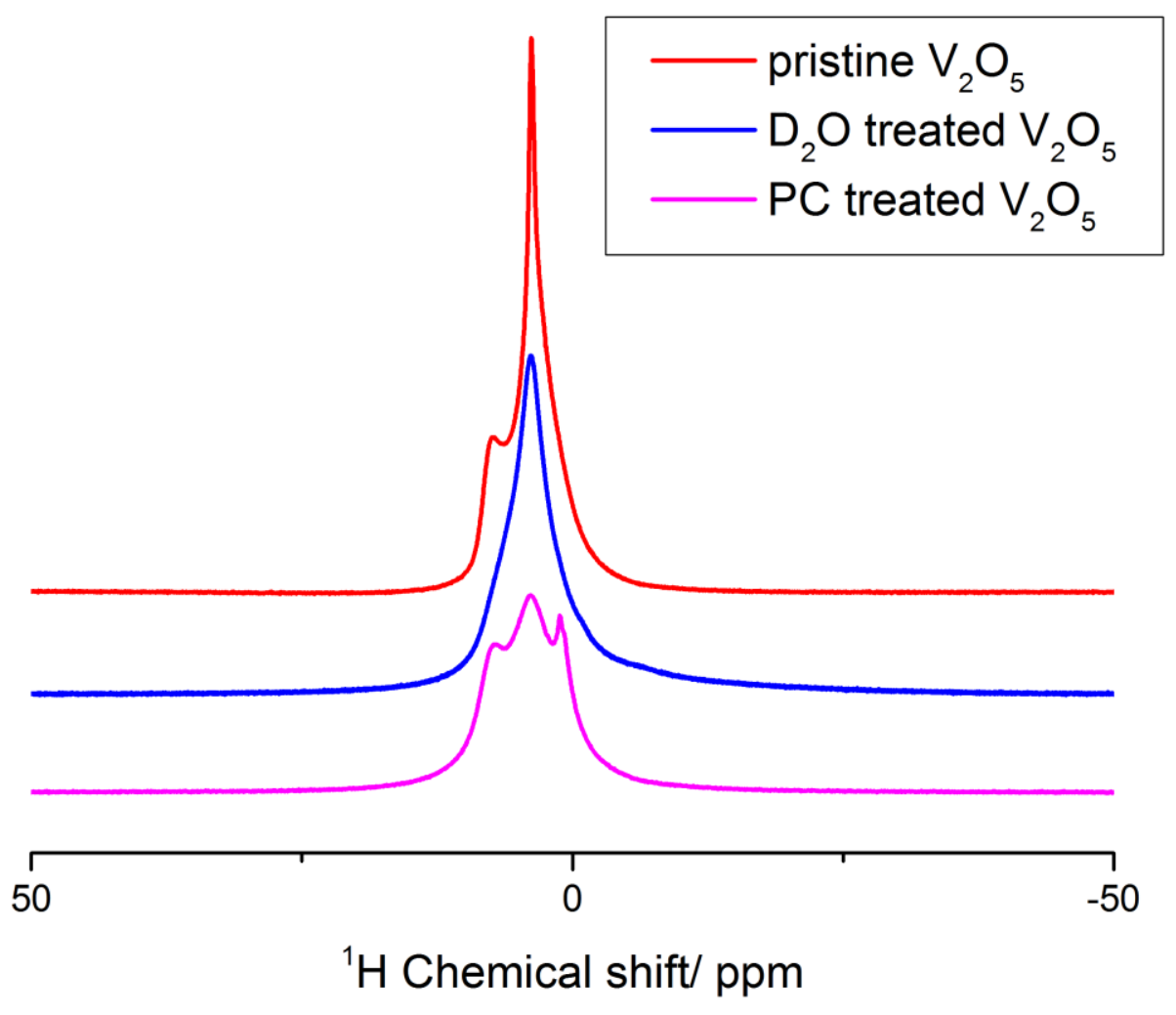

Figure S6. ${ }^{1} \mathrm{H}$ NMR spectra of pristine $\mathrm{V}_{2} \mathrm{O}_{5}, \mathrm{D}_{2} \mathrm{O}$ treated $\mathrm{V}_{2} \mathrm{O}_{5}$ and $\mathrm{PC}$ treated $\mathrm{V}_{2} \mathrm{O}_{5}$.

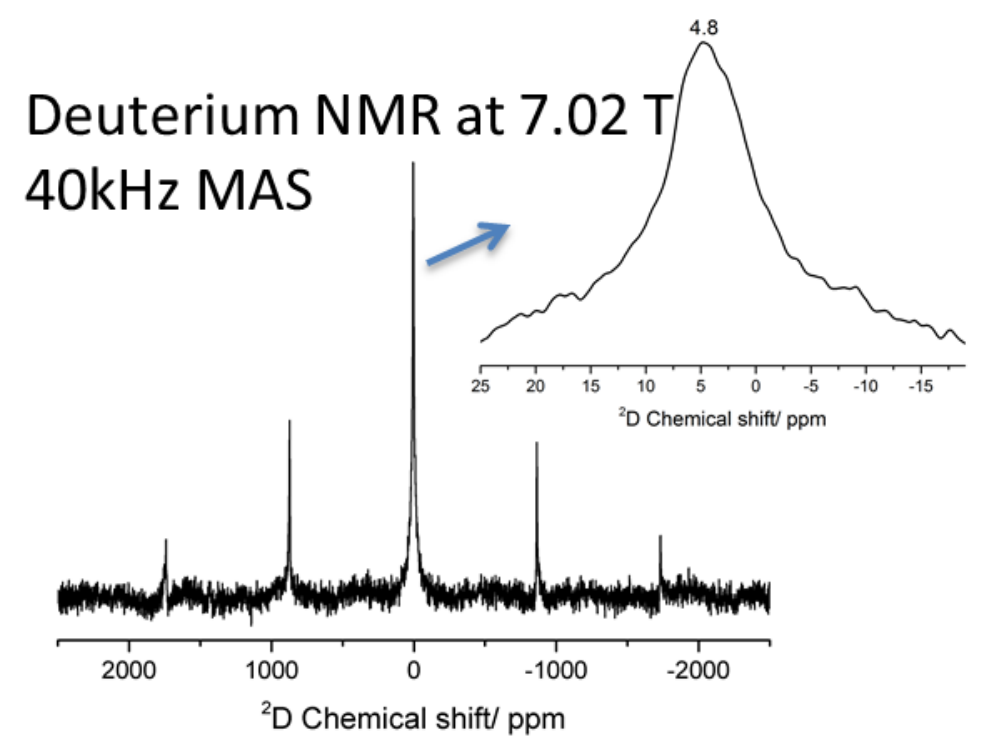


Figure S7. ${ }^{2} \mathrm{H}$ NMR spectra of $\mathrm{D}_{2} \mathrm{O}$ treated $\mathrm{V}_{2} \mathrm{O}_{5}$

\section{References:}

1 Grey, C. P.; Dupre, N., NMR Studies of Cathode Materials for Lithium-Ion Rechargeable Batteries. Chem. Rev. 2004, 104, 4493-4512.

2 Wang, H.; Senguttuvan, P.; Proffit, D. L.; Pan, B.; Liao, C.; Burrell, A. K.; Vaughey, J. T.; Key, B., Formation of MgO during Chemical magnesiation of Mg-ion battery materials. ECS Electrochem. Lett. 2015, 4, A90-A93. 